University of Nebraska - Lincoln

DigitalCommons@University of Nebraska - Lincoln

2000

\title{
MOLECULAR AND MORPHOMETRIC EVIDENCE FOR SEPARATE SPECIES OF UNCINARIA (NEMATODA: ANCYLOSTOMATIDAE) IN CALIFORNIA SEA LIONS AND NORTHERN FUR SEALS: HYPOTHESIS TESTING SUPPLANTS VERIFICATION
}

\author{
Steven A. Nadler \\ University of California - Davis, sanadler@ucdavis.edu \\ Byron J. Adams \\ University of Florida, byron_adams@byu.edu \\ Eugene T. Lyons \\ University of Kentucky, elyons1@uky.edu \\ Robert L. DeLong \\ NOAA \\ Sharon R. Melin \\ NOAA \\ Follow this and additional works at: https://digitalcommons.unl.edu/parasitologyfacpubs \\ Part of the Parasitology Commons
}

Nadler, Steven A.; Adams, Byron J.; Lyons, Eugene T.; DeLong, Robert L.; and Melin, Sharon R., "MOLECULAR AND MORPHOMETRIC EVIDENCE FOR SEPARATE SPECIES OF UNCINARIA (NEMATODA: ANCYLOSTOMATIDAE) IN CALIFORNIA SEA LIONS AND NORTHERN FUR SEALS: HYPOTHESIS TESTING SUPPLANTS VERIFICATION" (2000). Faculty Publications from the Harold W. Manter Laboratory of Parasitology. 706.

https://digitalcommons.unl.edu/parasitologyfacpubs/706

This Article is brought to you for free and open access by the Parasitology, Harold W. Manter Laboratory of at DigitalCommons@University of Nebraska - Lincoln. It has been accepted for inclusion in Faculty Publications from the Harold W. Manter Laboratory of Parasitology by an authorized administrator of DigitalCommons@University of Nebraska - Lincoln. 


\title{
MOLECULAR AND MORPHOMETRIC EVIDENCE FOR SEPARATE SPECIES OF UNCINARIA (NEMATODA: ANCYLOSTOMATIDAE) IN CALIFORNIA SEA LIONS AND NORTHERN FUR SEALS: HYPOTHESIS TESTING SUPPLANTS VERIFICATION
}

\author{
Steven A. Nadler, Byron J. Adams ${ }^{\star}$ Eugene T. Lyons†, Robert L. DeLong $\ddagger$, and Sharon R. Melin $\ddagger$ \\ Department of Nematology, University of California, Davis, California 95616-8668
}

\begin{abstract}
California sea lions (Zalophus californianus) and northern fur seals (Callorhinus ursinus) are each believed to host distinct hookworm species (Uncinaria spp.). However, a recent morphometric analysis suggested that a single species parasitizes multiple pinniped hosts, and that the observed differences are host-induced. To explore the systematics of these hookworms and test these competing hypotheses, we obtained nucleotide sequences of nuclear ribosomal DNA (D2/D3 28S, D18/D19 28S, and internal transcribed spacer [ITS] regions) from 20 individual hookworms parasitizing California sea lion and northern fur seal pups where their breeding grounds are sympatric. Five individuals from an allopatric population of California sea lions were also sampled for ITS-1 and D18/D19 28S sequences. The 28S D2/D3 sequences showed no diagnostic differences among hookworms sampled from individual sea lions and fur seals, whereas the 28S D18/D19 sequences had one derived (apomorphic) character demarcating hookworms from northern fur seals. ITS sequences were variable for 7 characters, with 4 derived (apomorphic) states in ITS-1 demarcating hookworms from California sea lions. Multivariate analysis of morphometric data also revealed significant differences between nematodes representing these 2 host-associated lineages. These results indicate that these hookworms represent 2 species that are not distributed indiscriminately between these host species, but instead exhibit host fidelity, evolving independently with each respective host species. This evolutionary approach to analyzing sequence data for species delimitation is contrasted with similarity-based methods that have been applied to numerous diagnostic studies of nematode parasites.
\end{abstract}

Stiles and Hassall (1899) originally reported hookworms (Uncinaria) of northern fur seals, Callorhinus ursinus Linneaus, from the Pribilof Islands in the Bering Sea. These specimens were later named Uncinaria lucasi Stiles (Stiles, 1901). However, because the description was unsatisfactory and the type material damaged, Baylis (1947) redescribed U. lucasi using new specimens obtained from C. ursinus (syn. C. alascanus, Callotaria alascana), also collected from the Pribilof Islands (St. Paul Island). Uncinaria lucasi has been reported primarily from species of fur seals, although exceptions include a report from Steller's sea lion, Eumetopias jubatus Schreber (Olsen, 1958), and a South American sea lion Otaria byronia Blainville (George-Nascimento et al., 1992).

Uncinaria lucasi is the only pinniped hookworm for which detailed life-cycle information is known (Olsen 1958, 1974; Olsen and Lyons, 1965; Lyons and Keyes, 1978, 1984; Lyons and Bigg, 1983; Lyons et al., 1997). Unlike hookworms from most terrestrial hosts, infections of adult $U$. lucasi occur only from parasitic $\mathrm{L}_{3}$ larvae passed to nursing pups in their mother's first milk. Adult hookworms are eliminated spontaneously from pups approximately 3 mo postinfection. Hookworm eggs develop to free-living $\mathrm{L}_{3}$ larvae in rookery soil, and $\mathrm{L}_{3}$ penetrate the skin of seals, or enter orally, and persist in tissues. The life cycle is completed when parasitic $\mathrm{L}_{3}$ are reactivated within lactating fur seals and transmitted to pups via milk. Hookworms in California sea lions are assumed to have a similar life cycle, and although no experimental infections have been completed,

Received 27 December 1999; revised 24 April 2000; accepted 24 April 2000.

* Department of Entomology and Nematology, University of Florida, Gainesville, Florida 32611-0620.

$\dagger$ Department of Veterinary Science, Gluck Equine Research Center, University of Kentucky, Lexington, Kentucky 40546-0099.

\$ National Marine Mammal Laboratory, Alaska Fisheries Science Center, National Marine Fisheries Service, NOAA, Sand Point Way, N.E., Seattle, Washington 98115-0070. circumstantial evidence supports this hypothesis (Lyons and Keyes, 1984; Lyons et al., in press).

The other species of hookworm described from otariids (fur seals and sea lions) is $U$. hamiltoni Baylis, obtained from $O$. byronia at Cape Dolphin in the Falkland Islands (Baylis, 1947). Baylis (1933) originally suggested that the specimens of Uncinaria from $O$. byronia were conspecific with specimens recovered from what he later asserted (Baylis, 1947) was a California sea lion Zalophus californianus Lesson (in 1933, he indicated uncertainty regarding whether the host was a California sea lion or a northern sea lion E. jubatus, syn. E. stelleri). Baylis (1947) and Dailey and Hill (1970) stated that specimens from $Z$. californianus had characteristics intermediate between $U$. lucasi and $U$. hamiltoni. Uncinaria hamiltoni has also been reported from the Australian sea lion Neophoca cinerea Péron and Lesueur (Beveridge, 1980). These descriptions and reports of Uncinaria have led to ambiguity concerning the presence of distinct hookworm species among different species of otariids.

A comparison of differences between $U$. lucasi and $U$. hamiltoni, according to their descriptions (Baylis, 1933, 1947), depicts $U$. lucasi as having: (1) a smaller buccal capsule with a slightly different shape than $U$. hamiltoni; (2) no thickening of the buccal capsule wall at its base, and no toothlike structures at the subdorsal angles of the border of the capsule; (3) smaller subventral teeth; (4) a shorter esophagus; and (5) a smaller bursa. U. hamiltoni has also been reported to have a shorter anterolateral ray relative to the other 2 rays, and the spicules of this species are described as being twice as long as those of $U$. lucasi. Other differences, related to hosts, have been reported more recently. For example, $\mathrm{L}_{3}$ hatched from eggs of hookworms from California sea lion pups are approximately $100 \mu \mathrm{m}$ shorter than those from northern fur seal pups (Lyons and Keyes, 1978), adults are distributed differently in the intestinal tracts of these hosts (Lyons and Keyes, 1984; Lyons et al., 1997), California sea lion pups exhibit intestinal petechiae that are more diffuse (Lyons et al., 1997), and adult hookworms live at least twice as long in California sea lions (Lyons et al., in 
press). George-Nascimento et al. (1992) found differences in nematode body size, prevalence of host skin lesions, and intensity of infection for hookworms parasitizing South American sea lions (O. byronia) and South American fur seals (Arctocephalus australis Zimmermann). They concluded that these differences were all host-induced and opined that there is "just one widely distributed hookworm species (Uncinaria lucasi Stiles ...), with different host races and geographic subspecies." (George-Nascimento et al., 1992).

In the present study, we investigated the specific status of Uncinaria taxa parasitizing 2 otariid species, the California sea lion and the northern fur seal. Morphometric features of these hookworm taxa were compared using multivariate statistical methods. Individual hookworms, collected primarily from rookeries where the host species are sympatric, were sequenced for regions of nuclear ribosomal DNA (2 regions of the $28 \mathrm{~S}$ subunit, and internal transcribed spacers [ITS]) and the distribution of character states among individuals used to assess lineage exclusivity and species status. The results and logic of this approach are contrasted to similarity-based methods that have been used to investigate nematode species using sequence data (e.g., Hung et al., 1997, 1999; Newton et al., 1998; Gasser et al., 1999; Heise et al., 1999).

\section{MATERIALS AND METHODS}

Uncinaria specimens were collected from hosts (otariid pups) on San Miguel and San Nicolas Islands, California, as described in Lyons et al. (1997). Uncinaria stenocephala Railliet was collected from an Arctic fox (Alopex lagopus Linneaus) from St. Paul Island, Alaska. Necator americanus Stiles were obtained from human hosts in Guatemala following anthelmintic treatment. Specimens collected for molecular analysis were preserved in $95-100 \%$ ethanol at field collection sites and stored in ethanol at $-20 \mathrm{C}$ when returned to the laboratory. Specimens collected for morphological analysis were fixed and stored in alcoholformalin-glycerine. Vouchers of the specimens used for morphological (UCDNC 3666-3668) and molecular (anterior and posterior ends only; voucher numbers in Table I) study were deposited in the University of California Davis Nematode Collection.

Measurements were made for 25 male and 25 female hookworms collected from each of 3 pups (1 northern fur seal pup from St. Paul Island, Alaska collected on 10 August 1960, 1 northern fur seal pup from San Miguel Island, California collected on 21 July 1996, and 1 California sea lion pup from San Miguel Island, California collected on 18 July 1996). Measurements for males included total length, width, buccal capsule depth, esophageal length, and spicule length (Table II); the first 4 of these measurements were also made for females, as was distance of vulva from the posterior end, and tail length (Table III). MANOVA, using Wilkes Lambda statistics, was used for comparison of these measurements (by sex of nematode) from each of the 3 hosts from the 2 localities.

DNA was extracted from the excised midbody of 25 individual hookworms (16 females, 9 males) obtained from 7 California sea lion pups and 6 northern fur seal pups (Table I) using a DNA binding ("glass milk") method involving isothiocyanate and guanidinium (ID Pure Genomic DNA Kit, ID Labs Biotechnology; London, Ontario, Canada). Twenty of these hookworms were obtained from sea lion or fur seal pups raised at sites where these 2 host species are sympatric (share the same rookery areas and soil, and thus are likely to be exposed to common $\mathrm{L}_{3}$ ); 5 hookworms ( 4 females and 1 male) were obtained from 2 California sea lion hosts on San Nicolas Island where fur seals do not co-occur (Table I). A region of nuclear ribosomal DNA (rDNA), including the $18 \mathrm{~S} 33^{\prime}$-end, ITS- 1 and ITS-2, 5.8S subunit, and $28 \mathrm{~S} 5$ '-end was amplified using the polymerase chain reaction (PCR). The strategy for design of ITS PCR primers (sequence positions according to Caenorhabditis elegans numbering, Ellis et al, 1986; GenBank X03680) was described previously (Nadler et al., 2000). These primers anneal to the $3^{\prime}$-end of the $18 \mathrm{~S}$ rDNA (forward [ $>$ ] primer no. 93, 2,635-2,653
5'-TTGAACCGGGTAAAAGTCG) and 5'-end of the 28S rDNA (reverse $[<]$ primer no. 94, 3,745-3,764 5'-TTAGTTTCTTTTCCTCCG CT). DNA from the D2/D3 region of the $28 \mathrm{~S}$ nuclear ribosomal subunit was amplified by PCR using $>$ primer no. 500 (4,078-4,100 5'-AC TTTGAAGAGAGAGTTCAAGAG) and < primer no. 501 (4,6814,700 5'-TCGGAAGGAACCAGCTACTA). DNA from the D18/D19 region of the $28 \mathrm{~S}$ nuclear ribosomal subunit was amplified by PCR using $>$ primer no. 527 (5,003-5,026 5'-CTAAGGAGTGTGTAAC AACTCACC) and $<$ primer no. 532 (6,067-6,090 5'-AATGACGA GGCATTTGGCTACCTT). Cycling parameters for the ITS rDNA amplifications consisted of an initial denaturation at $94 \mathrm{C}$ for $3 \mathrm{~min}$, followed by 33 cycles of $94 \mathrm{C}$ for $30 \mathrm{sec}, 56 \mathrm{C}$ for $30 \mathrm{sec}$, and $72 \mathrm{C}$ for $75 \mathrm{sec}$, and a postamplification extension at $72 \mathrm{C}$ for $5 \mathrm{~min}$. Cycling parameters for the D2/D3 rDNA amplifications consisted of an initial nucleic acid denaturation at $94 \mathrm{C}$ for $3 \mathrm{~min}$, followed by 33 cycles of $94 \mathrm{C}$ for $30 \mathrm{sec}, 54 \mathrm{C}$ for $30 \mathrm{sec}$, and $72 \mathrm{C}$ for $1 \mathrm{~min}$, and a postamplification extension at $72 \mathrm{C}$ for $7 \mathrm{~min}$. Cycling parameters for the D18/ D19 28S rDNA amplifications consisted of an initial nucleic acid denaturation at $94 \mathrm{C}$ for $3 \mathrm{~min}$, followed by 34 cycles of $94 \mathrm{C}$ for $30 \mathrm{sec}$, $54 \mathrm{C}$ for $30 \mathrm{sec}$, and $72 \mathrm{C}$ for $45 \mathrm{sec}$, and a postamplification extension at $72 \mathrm{C}$ for $7 \mathrm{~min}$. PCR amplifications were performed using a proofreading DNA polymerase (ID Proof, ID Labs Biotechnology, or Finnzymes DyNAzyme EXT, MJ Research, Watertown Massachusetts), 0.5 $\mu \mathrm{M}$ of each primer, $200 \mu \mathrm{M}$ deoxynucleoside triphosphates, and a $\mathrm{MgCl}_{2}$ concentration of $2 \mathrm{mM}$ (D2/D3 reactions) or $3 \mathrm{mM}$ (D18/D19 $28 \mathrm{~S}$ and ITS reactions) in a total reaction volume of $25 \mu 1$. Templates for direct sequencing of amplified DNA from individual nematodes were prepared by enzymatic treatment of PCR products using exonuclease I and shrimp alkaline phosphatase (PCR product presequencing kit, Amersham). Sequences were obtained from PCR templates using BigDye (Perkin-Elmer, Norwalk, Connecticut) terminator cycle sequencing chemistry and an ABI 377 automated DNA sequencer. All sequences were completely double-stranded for verification using reactions primed from the PCR primers (28S D2/D3) or a combination of PCR primers and internal primers (D18/D19 28S rDNA and ITS). Two internal sequencing primers were used for complete sequencing of the ITS region, < no. 264 (3,185-3,203 5'-CGTTTTTCATCGATACGCG) and $>$ no. 389 (3,231-3,250 5'-TGCAGACGCTTAGAGTGGTG), although only primers no. 93 and no. 264 were required to double-strand ITS-1. One internal sequencing primer was used for the D18/D19 28S rDNA region that was double-stranded $(5,054-5,649)$, $<$ no. 545 (5,662-5,685 5'-CCTTACCTACATTATTCTATCGAC). Sequence fragments were assembled and edited using Sequencher v 3.0 (Gene Codes, Ann Arbor, Michigan). Invariant flanking regions, corresponding to the PCR primers, were removed from the sequences before sequence alignment and analysis. Sequences were aligned initially using CLUSTAL X 1.53b (Thompson et al., 1997) and the resulting output was adjusted manually to improve homology statements.

\section{RESULTS}

\section{Hookworm measurements and morphometric analyses}

Males: There was an overall effect of host location (Alaska vs. California) on measurements of hookworms from northern fur seals $(P<0.0001)$ except for width and buccal capsule depth, which were not different. Therefore, separate analyses were used when data on male hookworms from northern fur seals from Alaska and California were compared with those from California sea lions. There was an overall difference between hookworms in northern fur seals (Alaska) and California sea lions $(P<0.0001)$. All measurements were different $(P<$ 0.05 ) except for esophageal length, which was not significantly different. When data from northern fur seals (California) were compared with data from California sea lions (Table II), there were differences in all measurements taken $(P<0.0001)$, including body width $(P<0.01)$.

Females: There were no significant differences between measurements of hookworms from northern fur seals from Alaska and California. Therefore, data from female hookworms of 


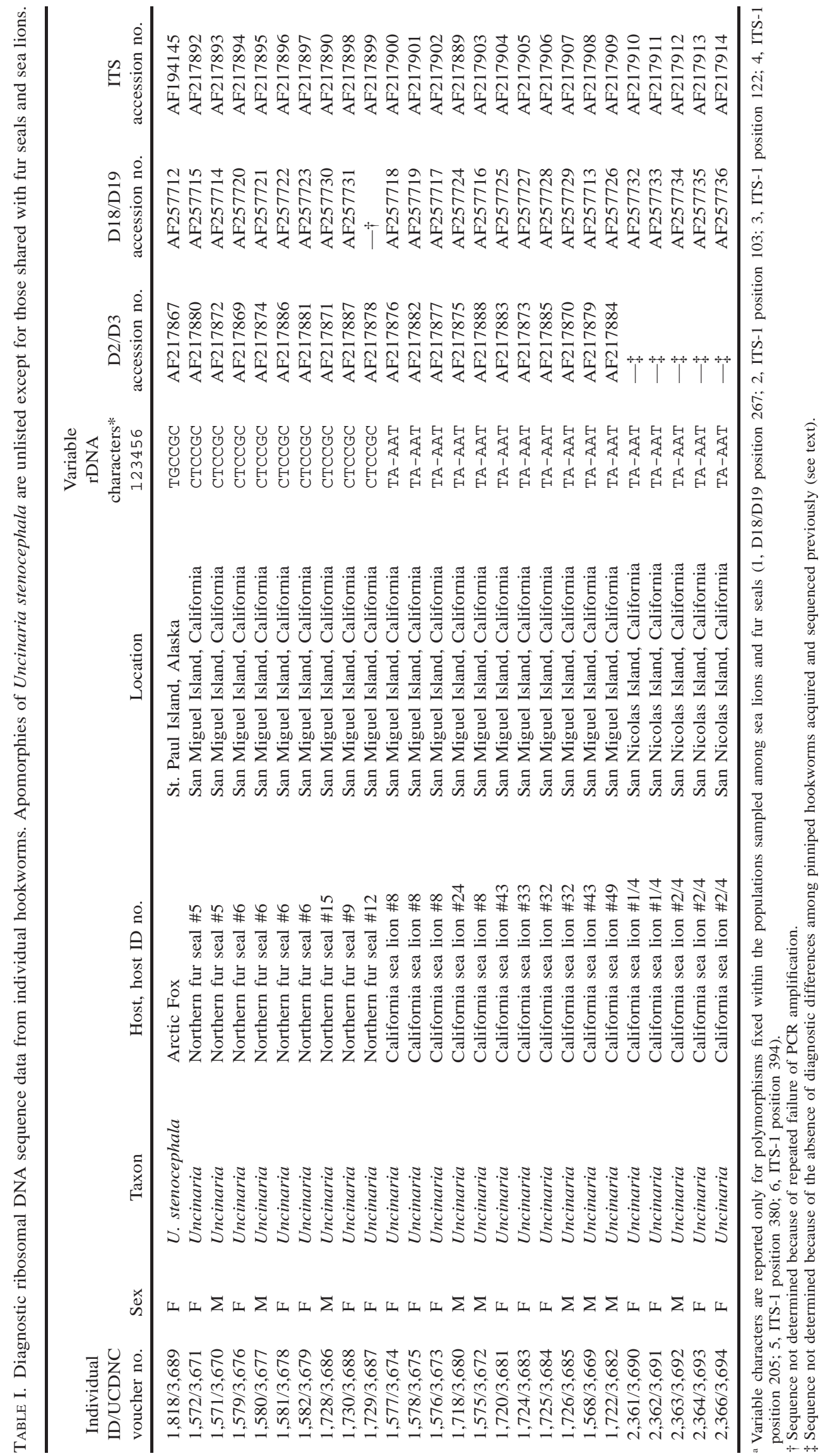


TABLE II. Measurements of 25 male Uncinaria, each from northern fur seal pups from Alaska and California, and from California sea lion pups, from California.

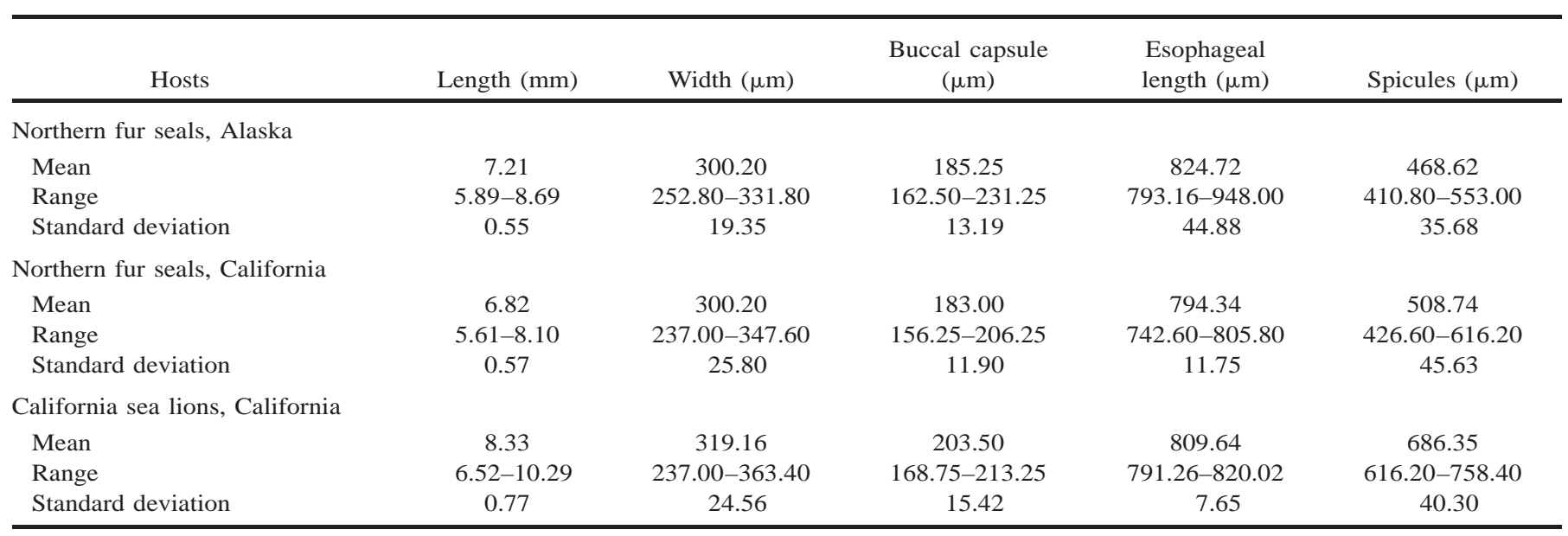

northern fur seals from both locations were combined for comparisons with hookworms from California sea lions. There was an overall effect of host species, northern fur seal versus California sea lion $(P<0.0001)$. Total length, width, buccal capsule depth, and esophageal length were different $(P<0.0001)$, but distance of the vulva from the posterior end and tail length were not (Table III).

\section{$28 S$ rDNA sequence data and analysis}

Ribosomal sequences from individual Uncinaria specimens have been deposited in GenBank (accession numbers in Table I). The D2/D3 28S rDNA region for all hookworms sampled from fur seals and sea lions was 561 nucleotides (nt) long (4 bases adjacent to 3 '-end of primer no. 501 could not be unambiguously determined in all individuals, and thus $557 \mathrm{nt}$ were deposited and compared in all individuals). The same region from $U$. stenocephala was also $561 \mathrm{nt}$, whereas the D2/D3 rDNA of N. americanus (GenBank AF217868) was 570 nt. The
D2/D3 rDNA sequences of 20 individual hookworms from California sea lions and northern fur seals (representing sympatric rookery sites) were invariant, with the exception of 2 worms (ID numbers 1,576 and 1,578, Table I) taken from the same host individual that were polymorphic $(\mathrm{A} / \mathrm{G})$ at position 79 in the multiple sequence alignment (alignment deposited in TreeBASE; Sanderson et al., 1994). Because of the invariant nature of these pinniped hookworm sequences, nematodes from sea lions on San Nicolas Island (the allopatric site) were not sampled for the D2/D3 rDNA region (Table I). The pinniped hookworms differed from $U$. stenocephala at 12 alignment positions (10 transitions, 2 transversions) and from $N$. americanus at 33 positions (24 transitions, 9 transversions) for the D2/D3 rDNA region. Average base composition for all taxa was 0.23 (A), $0.22(\mathrm{C}), 0.31(\mathrm{G})$, and $0.24(\mathrm{~T})$. An among-taxon test revealed no significant departure from base frequency homogeneity (chi-square $P=1.00$ ). Four insertion/deletion events including 2 3-base insertions, 1 2-base insertion, and 1 1-base

TABLE III. Measurements of 25 female Uncinaria, each from northern fur seal pups from Alaska and California, and from California sea lion pups, from California.

\begin{tabular}{|c|c|c|c|c|c|c|}
\hline \multicolumn{7}{|c|}{ Northern fur seals, Alaska } \\
\hline Range & $9.77-13.83$ & $331.80-426.60$ & $187.50-256.25$ & $804.22-840.05$ & $3.44-5.61$ & $187.50-300.00$ \\
\hline Standard deviation & 1.03 & 24.25 & 17.03 & 7.23 & 0.53 & 23.45 \\
\hline \multicolumn{7}{|c|}{ Northern fur seals, California } \\
\hline Range & $9.48-13.02$ & $300.20-442.40$ & $168.73-250.00$ & $805.80-832.66$ & $4.02-5.93$ & $156.25-268.75$ \\
\hline Standard deviation & 0.88 & 33.12 & 23.05 & 6.32 & 0.45 & 19.89 \\
\hline \multicolumn{7}{|c|}{ California sea lions, California } \\
\hline Mean & 12.61 & 412.70 & 241.50 & 828.85 & 4.55 & 214.75 \\
\hline Range & $11.06-13.79$ & $347.60-537.20$ & $218.75-268.75$ & $821.60-837.40$ & $3.48-5.53$ & $162.50-281.25$ \\
\hline Standard deviation & 0.82 & 41.13 & 12.74 & 4.32 & 0.46 & 32.62 \\
\hline
\end{tabular}

* Distance from posterior end.

$\dagger$ Length. 


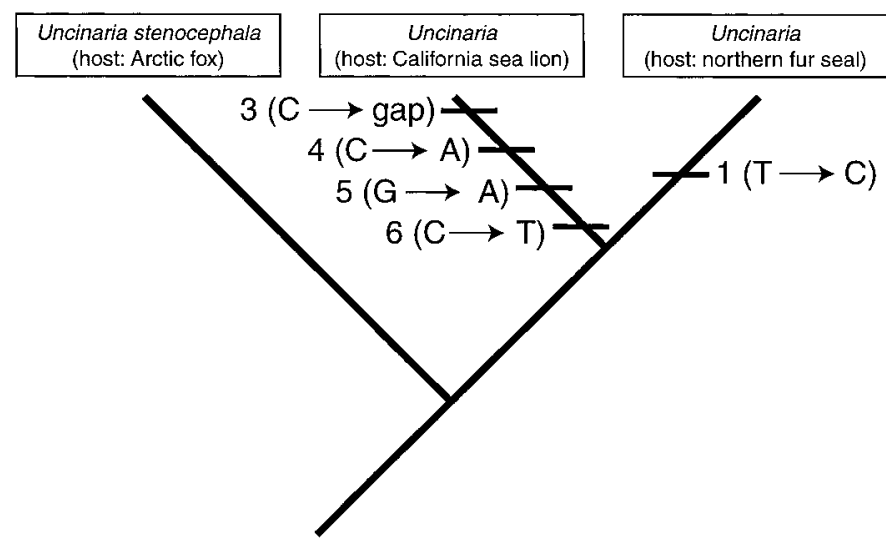

FIGURE 1. Evidence of character evolution and lineage independence among Uncinaria parasitizing Arctic foxes (Alopex lagopus), California sea lions (Zalophus californianus), and northern fur seals (Callorhinus ursinus) on the basis of outgroup comparison and parsimony analysis. Of 6 polymorphic rDNA nucleotides fixed within sampled populations (Table I), 1 D18/D19 character is autapomorphic for Uncinaria from northern fur seals (character 1, a transition). Four ITS- 1 rDNA sites (characters 3-6) are autapomorphic for Uncinaria from California sea lions (character-state changes include 2 transitions, 1 transversion, and 1 deletion). Character evolution for 1 potentially informative ITS-1 site (character 2, Table I) is ambiguous by parsimony criteria. The exclusive fixation of unique, derived character-states provides evidence of historical, and thus prospective, lineage independence for species delimitation.

insertion account for length variation between $N$. americanus and the other taxa. The region that was double-stranded for the D18/D19 28S rDNA sequences was $596 \mathrm{nt}$ in all sampled hookworms. The D18/D19 sequences of all individual hookworms from California sea lions and northern fur seals showed 1 difference (position 267, a transition) that was partitioned without exception according to host (Table I). Cladistic analysis of position 267 using outgroup comparison (U. stenocephala outgroup) provided evidence for the fixation of a derived character state among individual hookworms from northern fur seal hosts (Fig. 1). Two additional sequence differences (transitions between $\mathrm{C}$ and $\mathrm{T}$ ) were observed between the pinniped hookworms and $U$. stenocephala.

\section{ITS rDNA sequence data and analysis}

The amplified region that included the ITS rDNA subunits (partial 3 '-end 18S, ITS-1, 5.8S subunit, ITS-2 and partial 5'end 28S) from northern fur seals was $836 \mathrm{nt}$ long (6 nt adjacent to the $5^{\prime}$-end $18 \mathrm{~S}$ primer and $8 \mathrm{nt}$ adjacent to $3^{\prime}$-end $28 \mathrm{~S}$ primer could not be unambiguously determined, thus 822 nt were deposited and compared among taxa). In California sea lion hookworms and $U$. stenocephala, the amplified region was $835 \mathrm{nt}$ (821 nt deposited and compared). However, the same region in N. americanus (GenBank AF217891) was 1,090 nt (1,076 deposited and compared). Among Uncinaria, the ITS-1 region was $365 \mathrm{nt}$ (taxa from fur seals and U. stenocephala) or $364 \mathrm{nt}$ (taxa from sea lions); ITS-2 was $225 \mathrm{nt}$ in the pinniped Uncinaria, and $224 \mathrm{nt}$ in $U$. stenocephala. The multiple sequence alignment for pinniped Uncinaria and outgroup taxa (deposited in TreeBASE) contained 26 indels involving $1 \mathrm{nt}$ position, and 32 indels of more than $1 \mathrm{nt}$ position. These numerous, large indels resulted in several regions of ambiguity in the multiple alignment. Because of doubts about positional homology statements for the $N$. americanus sequence relative to other taxa, this outgroup was excluded from additional comparisons; this reduced the number of alignment indels to 4 , all of which involved single nucleotide events. Seven ITS sites were found to vary among hookworms sampled from fur seals and sea lions. Five of the 7 variable sites were in the ITS- 1 region, and these 5 dimorphic characters were partitioned without exception according to host (Table I). Differences between these host-specific sequences involved 2 transitions, 2 transversions, and an insertion/deletion event. Positions and differences for these sites (character for fur seal hookworms/sea lion hookworms) were: 103 (T/A), 122 (C/gap), 205 (C/A), 380 (G/A), and 394 (C/T), with positions numbered according to the multiple alignment of Uncinaria taxa (without $N$. americanus). All 4 nt substitutions involved either an adenine or thymine, and overall, ITS-1 was $\mathrm{A}-\mathrm{T}$ rich $(\mathrm{A}=0.21 ; \mathrm{C}=0.22 ; \mathrm{G}=0.27 ; \mathrm{T}=0.30)$ among Uncinaria, and among Uncinaria plus $N$. americanus $(\mathrm{A}=$ $0.23, \mathrm{C}=0.21, \mathrm{G}=0.25, \mathrm{~T}=0.31$ ). An among-taxon comparison revealed no significant departure from base frequency homogeneity (chi-square for Uncinaria only, $P=0.95$; for Uncinaria plus $N$. americanus $P=0.89$ ). Two ITS-2 sites were found to vary among hookworms sampled from northern fur seals and California sea lions. These sites included 2 putative autapomorphies (one for hookworms from northern fur seals, the other for hookworms from California sea lions); however, additional hookworms were not sequenced for ITS-2 because sufficient informative character data were obtained from other rDNA regions.

Cladistic analysis of the 5 variable ITS- 1 characters using outgroup comparison (U. stenocephala outgroup) revealed that 4 of the sites (positions 122, 205, 380, and 394) provided evidence for the fixation of a derived character state in hookworms from California sea lion hosts (Fig. 1).

\section{DISCUSSION}

The ITS rDNA region appears to be a useful molecular marker for investigating evolutionary patterns among nematode taxa at various levels of the taxonomic hierarchy (Powers et al., 1997). Hookworm species from different genera, and populations assumed to represent single species, have been investigated by several authors using ITS sequences, or specific tests developed from ITS PCR products (Gasser et al., 1996, 1998; Monti et al., 1998; Romstad et al., 1998). Other molecular markers, including the $3^{\prime}$ untranslated region of a cAMP-dependent protein kinase (Hawdon, 1996) and the cysteine protease AcCP1 (Mieszczanek and Wedrychowicz, 1999), have been used to discriminate genera and species of hookworms. The D2/D3 expansion domains of the nuclear 28S rDNA subunit are another sequence region that has been successfully used for diagnosing nematode species, including specimens that have been briefly fixed using formalin (Thomas et al., 1997).

The present study permits a direct comparison of the $28 \mathrm{~S}$ and ITS regions of the nuclear rDNA repeat among some Ancylostomatidae. The pattern of substitution in these regions is clearly different, with the ITS region evolving at a higher rate, which is consistent with expectations of lower constraint for spacer sequences relative to sequences of the functional ribosome such as the D2/D3 region (Baldwin et al., 1995). The ITS region also 
appears less constrained with respect to substitution type. For example, on the basis of observed (uncorrected) substitutions, the D2/D3 rDNA region revealed the expected transition(ti): transversion(tv) bias (ti:tv of 2.11 [U. stenocephala vs. N. americanus] to 5.0 [U. stenocephala vs. hookworms of California sea lions and northern fur seals]), whereas the ITS region showed less transition bias (ti:tv of 1.0 [hookworms of California sea lions vs. hookworms of northern fur seals] to 2.33 [hookworms of California sea lions vs. U. stenocephala]). In addition, the alignment of the D2/D3 region contained only 4 indels (2 3-base, 12 -base, and 1 1-base) relative to 36 substitution events. By contrast, in the alignment of the ITS region including $N$. americanus, there were 58 indels relative to 112 substitution events. This comparison of indels to substitutions assumes that multiple bases comprising an indel represent a single insertion-deletion event. If the multiple-base indels result from the cumulative total of separate single events, the proportion of indels to detectable single base substitutions would be even greater for the ITS region (maximum of 271 indel events to 112 single nucleotide substitutions). These findings suggest that ITS rDNA is less constrained relative to type and rate of substitutions than the D2/D3 rDNA among these hookworms.

Adult Uncinaria from northern fur seal pups are significantly different from those in California sea lion pups on the basis of morphometry; this difference was found irrespective of which locality was used for comparison of the northern fur seal hookworms (California or Alaska). Although Baylis (1933, 1947) described certain qualitative differences between $U$. lucasi and $U$. hamiltoni, we focused our morphological study on quantitative features, because the structures discussed by Baylis varied by angle of view, and seemed to require subjective interpretation. Our sampling revealed no sequence differences for ITS-1 between allopatric populations of adult hookworms parasitizing California sea lions. Sequences from hookworms representing allopatric populations from northern fur seals were not determined (Alaska specimens collected in 1960 and used for morphometric analysis could not be amplified successfully by PCR, presumably because of DNA damage resulting from fixation and storage effects); however, genetic comparisons of hookworm samples from California and Alaska are warranted because male specimens from these hosts showed significant differences for certain measurements. Genetic and morphometric variation among individual hookworms sampled from sympatric northern fur seals and California sea lions were partitioned exclusively according to host species. For example, the 6 rDNA differences (Table I) among individual hookworms taken from sympatric northern fur seals and California sea lions are fixed within each respective host, but vary between host species. Thus, these genetic data provide independent evidence that these 2 diagnosable hookworm taxa do not develop to adults in the intestines of both California sea lions and northern fur seals; instead, each taxon appears restricted to a single host species. Likewise, these 2 taxa are diagnosable on the basis of morphometric data, providing additional evidence for host specificity.

In addition to being diagnosably different (and thus satisfying the criterion of phylogenetic species sensu Nixon and Wheeler, 1990; Wheeler, 1999), there is evidence that these 2 Uncinaria lineages from otariids have been evolving independently in the past and, therefore, can be delimited as species using more the- oretically rigorous criteria. Regarding the status of species, we make the distinction between diagnosis and delimitation as the latter having meaning in an explicit evolutionary context. Wary of confusing what species are with how they can be discovered, we advocate searching for ontologically "real" species (our preference being the evolutionary species concept of Wiley and Mayden, 2000) by using amended discovery operations of the phylogenetic species concept (Frost and Kluge, 1994; Adams, 1998). This approach focuses on "how do we know we have species?" (epistemology) within the context of the theoretical or ontological framework provided by our species concept, i.e., "do we have species?" The former (epistemological) question is typically addressed without an explicit theoretical framework when comparisons of pairwise sequence differences (or phenetic similarity) are used to assess if a certain taxon merits species status (e.g., Hung et al., 1997, 1999; Romstad et al., 1998; Gasser et al., 1999; Heise et al., 1999). For example, in a sequence-based study of equine strongylids (Cylicocyclus), Hung et al. (1997) stated that they "compared DNA sequences ... of rDNA of C. ashworthi and C. nassatus in order to provide molecular data that these taxa represent different species, and to establish a rapid polymerase chain reaction (PCR)-based method for their delineation." This near-tautological activity of searching for data that support or "delineate" the a priori expectation of species does not involve potential refutation, but verification, and is of limited scientific merit (Popper, 1968; Lakatos, 1970; Kluge, 1997). No doubt the impetus for some recent studies of parasites has been to provide molecular markers that discriminate among morphologically indistinguishable life history stages, e.g., eggs or juveniles, for species that are otherwise accepted as "well established" on the basis of distinctiveness of adults and taxonomic differential diagnoses (Gasser et al., 1998; Monti et al., 1998; Mieszczanek and Wedrychowicz, 1999). However, even this approach to using molecular data for verification of "species" has potential caveats, e.g., if the differential diagnosis of the original "well-established" species was confounded by host-induced morphological differences or other pitfalls.

Studies that seek to identify and use all observed sequence differences to define species (e.g., Hung et al., 1997), typically through application of a genetic "yardstick", are problematic for several additional reasons. Potential problems include variation in the rate of sequence evolution among lineages, which may confound interpretations of pairwise sequence divergence, and the requirement to set a boundary defining the minimum amount of sequence divergence that merits species status. For example, Uncinaria taxa from pinnipeds display simple sequence differences (formula of Newton et al., 1998) of $1.1 \%$ for ITS- 1 and $0.88 \%$ for ITS-2, whereas the average difference between these pinniped hookworms and $U$. stenocephala is $7.4 \%$ for ITS-1 and $10.6 \%$ for ITS-2. How can such measures of genetic differentiation be interpreted with respect to evaluating species status? Even if the taxa under consideration have a constant rate of sequence evolution for the gene investigated, interpretation of sequence divergence for exemplar taxa may be confounded by the taxa sampled. Is our "genetic yardstick" comparison based on pairs of sister species, or is information available only for more distantly related congeners? Comparison of pairwise or average similarity between taxa also ignores the risks of defining evolutionary groups (in this case species) 
on the basis of all types of differences and similarities, including plesiomorphies. Perhaps, most importantly, using a genetic yardstick for defining species entails the assumption that some characteristic (minimum) threshold of genetic change is a requisite property of species; however, this assumption is not consistent with empirical evidence on the genetics of species differences (Templeton, 1981). The lack of consistent correlation between genetic differentiation and taxonomic rank indicates that interpreting the genetics of species differences requires a different emphasis, one that focuses on identifying evolutionary taxa and their novelties (Cracraft, 1989).

We view species as time-extended individuals (lineages) (Ghiselin, 1974, 1987, 1997; Hull, 1978; but see also Baum, 1998) and require evidence of historical lineage independence (in the form of autapomorphic characters) to delimit species. Testing the hypothesis of lineage independence in any particular case requires phylogenetic interpretation of data and the potential for failure to recover such lineages (Adams, 1998). This method does not assume that only lineages with autapomorphies are species (which would conflate an epistemological approach with a theoretical concept of what species are); rather, this approach represents an objective method for using character-state data (such as nucleotide sequences) to delimit species by hypothesis testing (see Adams, 1998). For example, assuming $U$. stenocephala shares a most recent common ancestor with the 2 diagnosable hookworms parasitizing otariids, the different homologous character states shared by these taxa can be polarized. Of 5 ITS-1 sites with fixed differences between the hookworms sampled from the 2 species of otariids, 4 have shared states between $U$. stenocephala and Uncinaria from northern fur seals. The most parsimonious interpretation of these ITS-1 characters is that hookworms from California sea lions have evolved 4 unique, derived character states (autapomorphies). However, these 4 autapomorphic characters are not sufficient to distinguish hookworms from California sea lions and northern fur seals as unique in an evolutionary sense (although the ITS-1 sites provide diagnosable differences between hookworms from each host). The necessary additional data comes from cladistic analysis of the D18/D19 site, which provides evidence of an autapomorphy for hookworms from northern fur seals (Fig. 1). Thus, hookworms from California sea lions and northern fur seals each have one or more autapomorphies as evidenced from cladistic analysis of these rDNA data. The fact that these autapomorphic states are fixed among sampled individuals, and not shared with any other lineage, is evidence of historical lineage exclusivity. Such historical independence supports the hypothesis that these lineages represent distinct species. Thus, in contrast to a single, widespread hookworm species with multiple host species, these data support the notion of 2 distinct hookworm species as proposed in the early descriptions of Baylis (1933, 1947). One potential caveat to this interpretation is that although autapomorphies have been inferred for the 2 otariid hookworm species in question, these unique derived states cannot be unquestionably determined until their homologues are examined among all other species of Uncinaria. Likewise, confidence in the exclusive and fixed nature of these autapomorphies would be increased by sampling hookworms and hosts from a larger geographic range, although the geographic range for parasite transmission (rookeries) is much more restricted than host ranges in the ocean.
In the context of this evolutionary interpretation, it is also notable that California sea lion pups that died at rookeries on San Miguel Island had twice the number of hookworms in comparison with northern fur seal pups, and there appeared to be differences in hookworm location, pathogenesis (Lyons et al., 1997), and longevity (Lyons et al., in press) between these hosts. It was previously unclear if this was due to differential effects of 1 hookworm species in 2 host species, or as a consequence of distinct species of hookworms in these 2 hosts. We provide evidence that Uncinaria of northern fur seals and California sea lions are 2 distinct species. However, we cannot confirm with confidence that the species in northern fur seals and California sea lions correspond to U. lucasi and U. hamiltoni, respectively. Although the description of $U$. lucasi is consistent with specimens obtained from hosts collected in California, analysis of morphometric data revealed significant differences between certain characters of male hookworms obtained from northern fur seals collected in California and Alaska. Because we lack sequence data for the Alaska specimens, we cannot use genetic data to assess topotype specimens of $U$. lucasi. Likewise, the description of $U$. hamiltoni is based on specimens obtained from a South American sea lion, and morphological observations suggest that hookworms of California sea lions may be intermediate between those found in northern fur seals and South American sea lions (Baylis, 1947; Dailey and Hill, 1970). Baylis (1947) concluded, “. . . it does not seem desirable to regard the Californian species as distinct until it has been more fully investigated (p. 311)." Having done so, the onus of evidence must be directed to comparative analysis of other hookworms infecting pinnipeds.

\section{ACKNOWLEDGMENTS}

We thank Pamela Yochem and Brent Stewart, Hubbs-Sea World Research Institute, San Diego, California, for collecting hookworms on San Nicholas Island. We also are grateful to George Greer, director for Peace Corps in Guinea, for providing specimens of N. americanus, and to Michelle Smith, University of Kentucky, Lexington, Kentucky, for consultation on statistical analysis of morphometric data.

\section{LITERATURE CITED}

ADAMS, B. J. 1998. Species concepts and the evolutionary paradigm in modern nematology. Journal of Nematology 30: 1-21.

Baldinin, B. G., M. J. Sanderson, J. M. Porter, M. F. Wojciechowski, C. S. CAmpbell, and M. J. Donoghue. 1995. The ITS region of nuclear ribosomal DNA: A valuable source of evidence on angiosperm phylogeny. Annals of the Missouri Botanical Garden 82: 247-277.

BAUM, D. A. 1998. Individuality and the existence of species through time. Systematic Biology 47: 641-653.

BAYLIS, H. A. 1933. A new species of the nematode genus Uncinaria from a sea-lion, with some observations on related species. Parasitology 25: 308-316.

. 1947. A redescription of Uncinaria lucasi Stiles, a hookworm of seals. Parasitology 38: 160-162.

Beveridge, I. 1980. Uncinaria hydromidis sp. N. (Nematoda: Ancylostomatidae) from the Australian water rat, Hydromis chrysogaster. Journal of Parasitology 66: 1027-1031.

Cracraft, J. 1989. Speciation and its ontology: The empirical consequences of alternative species concepts for understanding patterns and processes of differentiation. In Speciation and its consequences, D. Otte, and J. A. Endler (eds.). Sinauer Associates, Sunderland, Massachusetts, p. 28-59. 
DAILEY, M. D., AND B. L. HiLl. 1970. A survey of metazoan parasites infecting the California (Zalophus californianus) and Steller (Eumetopias jubatus) sea lion. Bulletin of the Southern California Academy of Science 69: 126-132.

Ellis, R. E., J. E. Sulston, And A. R. Coulson. 1986. The rDNA of C. elegans: Sequence and structure. Nucleic Acids Research 14: 2345-2364.

Frost, D. R., And A. G. Kluge. 1994. A consideration of epistemology in systematic biology, with special reference to species. Cladistics 10: $259-294$.

Gasser, R. B., J. R. Monti, Q. B.-Zhen, A. M. Polderman, P. Nansen, AND N. B. Chilton. 1998. A mutation scanning approach for the identification of hookworm species and analysis of population variation. Molecular and Biochemical Parasitology 92: 303-312.

, L. E. Stewart, and R. Speare. 1996. Genetic markers in ribosomal DNA for hookworm identification. Acta Tropica 62: 1521.

, W. G. Woods, M. A. Huffman, J. Blotkamp, and A. M. PoldERMAN. 1999. Molecular separation of Oesophagostomum stephanostomum and Oesophagostomum bifurcum (Nematoda: Strongyloidea) from non-human primates. International Journal for Parasitology 29: 1087-1091.

George-Nascimento, M., M. Lima, And E. Ortiz. 1992. A case of parasite-mediated competition? Phenotypic differentiation among hookworms Uncinaria sp. (Nematoda: Ancylostomatidae) in sympatric and allopatric populations of South American sea lions Otaria byronia, and fur seals Arctocephalus australis (Carnivora: Otariidae). Marine Biology 112: 527-533.

Ghiselin, M. T. 1974. A radical solution to the species problem. Systematic Zoology 23: 536-544.

1987. Species concepts, individuality, and objectivity. Biology and Philosophy 2: 127-143.

1997. Metaphysics and the origin of species. State University of New York Press, Albany, New York, 377 p.

Hawdon, J. M. 1996. Differentiation between the human hookworms Ancylostoma duodenale and Necator americanus using PCR-RFLP. Journal of Parasitology 82: 642-647.

Heise, M., C. Epe, AND T. SChNiEder. 1999. Differences in the second internal transcribed spacer (ITS-2) of eight species of gastrointestinal nematodes of ruminants. Journal of Parasitology 85: 431-435.

Hull, D. L. 1978. A matter of individuality. Philosophy of Science 45: 335-360.

Hung, G.-C., N. B. Chilton, I. Beveridge, A. McDonnell, J. R. LichTENFELS, AND R. B. GASSER. 1997. Molecular delineation of Cylicocyclus nassatus and C. ashworthi (Nematoda: Strongylidae). International Journal for Parasitology 27: 601-605.

-, , X. Q. ZhU, J. R. Lichtenfels, And R. B. GASSER. 1999. Molecular evidence for cryptic species within $C y$ licostephanus minutus (Nematoda: Strongylidae). International Journal for Parasitology 29: 285-291.

KLugE, A. G. 1997. Testability and the refutation and corroboration of cladistic hypotheses. Cladistics 13: 81-96.

LAKATOS, I. 1970. Falsification and the methodology of scientific research programmes. In Criticism and the growth of knowledge, I. Lakatos, and A. Musgrave (eds.). Cambridge University Press, London, U.K., p. 91-196.

Lyons, E. T., AND M. A. BIGG. 1983. On the longevity of larvae of the hookworm Uncinaria lucasi in tissues of northern fur seals ( Callorhinus ursinus). Journal of Parasitology 69: 442-443.

—, R. L. Delong, S. R. Melin, and S. C. Tolliver. 1997. Uncinariasis in Northern fur seal and California sea lion pups from California. Journal of Wildlife Diseases 33: 848-852.

, F. M. Gulland, S. R. Melin, S. C. Tolliver, and T. R. SPRAKER. 2000. Comparative biology of Uncinaria spp. in the California sea lion (Zalophus californianus) and the northern fur seal (Callorhinus ursinus) in California. Journal of Parasitology, in press.

-, AND M. C. KeYES. 1978. Observations on the infectivity of parasitic third-stage larvae of Uncinaria lucasi Stiles 1901 (Nematoda: Ancylostomatidae) of Northern fur seals, Callorhinus ursi- nus Linn., on St. Paul Island, Alaska. Journal of Parasitology 64: 454-458.

- AND - 1984. Further indication of viability of larvae of the hookworm (Uncinaria lucasi) for several years in tissues of Northern fur seals (Callorhinus ursinus). Journal of Parasitology 70: $459-460$.

MieszCZANeK, J., AND H. Wedrychowicz. 1999. Differentiation of the two dog hookworm species using PCR. Acta Parasitologica 44: 8183.

Monti, J. R., N. B. Chilton, B. Z. Qian, and R. B. Gasser. 1998. Specific amplification of Necator americanus or Ancylostoma duodenale DNA by PCR using markers in ITS-1 rDNA, and its implications. Molecular and Cellular Probes 12: 71-78.

Nadler, S. A., E. P. Hoberg, D. S. S. Hudspeth, and L. G. Rickard. 2000. Relationships of Nematodirus species and Nematodirus battus isolates (Nematoda: Trichostrongyloidea) based on nuclear ribosomal DNA sequences. Journal of Parasitology 86: 588-601.

Newton, L. A., N. B. Chilton, I. Beveridge, and R. B. Gasser. 1998. Genetic evidence indicating that Cooperia surnabada and Cooperia oncophora are one species. International Journal for Parasitology 28: 331-336.

Nixon, K. C., AND Q. D. WheELER. 1990. An amplification of the phylogenetic species concept. Cladistics 6: 211-224.

Olsen, O. W. 1958. Hookworms, Uncinaria lucasi Stiles, 1901, in fur seals, Callorhinus ursinus (Linn.), on the Pribilof Islands. Transactions of Twenty-third North American Wildlife Conference, Wildife Management Institute, Washington, D.C., p. 152-175.

- 1974. Animal parasites: Their life cycles and ecology, 3rd ed. University Park Press, Baltimore, Maryland, 562 p.

, AND E. T. LyONs. 1965. Life cycle of Uncinaria lucasi Stiles, 1901 (Nematoda: Ancylostomatidae) of fur seals, Callorhinus ursinus Linn., on the Pribilof Islands, Alaska. Journal of Parasitology 51: $689-700$.

POPPER, K. 1968. The logic of scientific discovery. Harper and Row, New York, New York, 479 p.

Powers, T. O., T. C. Todd, A. M. Burnell, P. C. B. Murray, C. C. Fleming, A. L. Szalanski, B. J. Adams, and T. S. Harris. 1997. The rDNA internal transcribed spacer region as a taxonomic marker for nematodes. Journal of Nematology 29: 441-450.

Romstad, A., R. B. Gasser, P. Nansen, A. M. Polderman, and N. B. Chilton. 1998. Necator americanus (Nematoda: Ancylostomatidae) from Africa and Malaysia have different ITS-2 rDNA. International Journal for Parasitology 28: 611-615.

Sanderson, M. J., M. J. Donoghue, W. Piel, And T. ERIKSSON. 1994. TreeBASE: A prototype database of phylogenetic analyses and an interactive tool for browsing the phylogeny of life. American Journal of Botany 81: 183 .

StILES, C. W. 1901. Uncinariasis (Anchylostomiasis) in man and animals in the United States. Texas Medical News 10: 523-532. , AND A. HASSALl. 1899. Internal parasites of the fur seals. In U. S. Treasury Department. The fur seals and fur-seal islands of the North Pacific Ocean (David Starr Jordan Report 1899). Pt. 3, p. 99-177.

Templeton, A. R. 1981. Mechanisms of speciation-A population genetic approach. Annual Review of Ecology and Systematics 12: $23-48$.

Thomas, W. K., J. T. Vida, L. M. Frisse, M. Mundo, And J. G. BaldWIN. 1997. DNA sequences from formalin-fixed nematodes: Integrating molecular and morphological approaches to taxonomy. Journal of Nematology 29: 250-254.

Thompson, J. D., T. J. Gibson, F. Plewniak, F. Jeanmougin, and D. G. Higains. 1997. The CLUSTAL-X windows interface: Flexible strategies for multiple sequence alignment aided by quality analysis tools. Nucleic Acids Research 25: 4876-4882.

WHEELER, Q. D. 1999. Why the phylogenetic species concept?-Elementary. Journal of Nematology 31: 134-141.

WiLEy, E. O., AND R. L. MAYDEN. 2000. The evolutionary species concept. In Species concepts and phylogenetic theory: A debate, Q. D. Wheeler and R. Meier (eds.). Columbia University Press, New York, New York, p. 70-224. 